\title{
A Case Study of Mentoring Deaf Academics: The PAH!* (Success) Academic Writing Retreat
}

\author{
Amber E. Marchut ${ }^{1 *}$, Kimberly K. Pudans-Smith ${ }^{2}$, \\ Merrilee R. Gietz ${ }^{3}$, Jean F. Andrews ${ }^{1}$, M. Diane Clark ${ }^{*}$ \\ ${ }^{1}$ Department of Deaf Studies and Deaf Education, Lamar University, MLK Blvd., Beaumont, TX, USA \\ ${ }^{2}$ Department of ASL, Gallaudet University, Washington, DC, USA \\ ${ }^{3}$ Department of Communication Sciences and Disorders, American Sign Language Interpreting Program, University of Houston, \\ Houston, Texas, USA \\ Email: *amarchut@lamar.edu, kimberly.pudans-smith@gallaudet.edu, \\ mrgietz@uh.edu, jean.andrews@lamar.edu, ‘diane.clark@lamar.edu
}

How to cite this paper: Marchut, A. E., Pudans-Smith, K. K., Gietz, M. R., Andrews, J. F., \& Clark, M. D. (2021). A Case Study of Mentoring Deaf Academics: The PAH! ${ }^{*}$ (Success) Academic Writing Retreat. Creative Education, 12, 176-192. https://doi.org/10.4236/ce.2021.121013

Received: December 11, 2020

Accepted: January 22, 2021

Published: January 25, 2021

Copyright (c) 2021 by author(s) and Scientific Research Publishing Inc. This work is licensed under the Creative Commons Attribution International License (CC BY 4.0).

http://creativecommons.org/licenses/by/4.0/

\begin{abstract}
While the goal of increasing numbers of underrepresented faculty members, especially Deaf professionals, has been accomplished to some extent, many are stymied in publishing their dissertation findings in peer-reviewed journals, and therefore have difficulty earning tenure. To address this need, a case study approach was utilized to investigate the development of Deaf professionals' academic writing during a five-day writing retreat. This paper discusses specific academic writing challenges including organizing ideas, finding an appropriate journal, editing, submitting, as well as handling peer reviews, rejections, and revisions. Information is provided on the final writing products, types of support, guidance, and mentorship that were employed. Findings showed that $75 \%$ of papers worked on during the retreat were successfully published in peer-reviewed journals. The importance of published work by Deaf scholars and plans for future retreats are described.
\end{abstract}

\section{Keywords}

Deaf Academics, Mentoring Deaf Scholars, Community of Practice, Writing Retreat

\section{Introduction}

Many institutions of higher education require faculty to publish research articles

*PAH! Means "finally" or "success at last" in American Sign Language. It includes a mouth movement that if voiced would sound like "pah!”. This usage is extremely positive and upbeat, signifying overcoming something that was difficult. 
in peer-reviewed journals in order to keep their jobs, as well as earn raises and promotions. While they are underrepresented, more Deaf professionals are accepting jobs in postsecondary programs and face the "publish or perish" dictum, as excelling at teaching is not enough. Deaf faculty are held to the same standards and must publish to survive in academia. Unfortunately, for Deaf professionals, this standard has become a barrier for tenure, promotion and raises (Smith \& Andrews, 2015). In other cases, this has led to lawsuits because Deaf faculty are discriminated against and not provided with consistent mentoring as are hearing faculty (Collier v. Texas Tech University, 2011). The situation at hand is that few Deaf faculty who are teaching are publishing their work in peer-reviewed journals (Smith \& Andrews, 2015; Woodcock et al., 2007). While increasing numbers of Deaf individuals complete their dissertation, few publish their findings in peer-reviewed journals (Andrews et al., 2015). One reason seems to be the trauma associated with years of drill on auditory phonology while learning to read (a skill that is typically not accessible; Paul \& Wang, 2012) while another reason may be that Deaf academics find it a struggle to find the "right" writing mentor who can provide them with support and guidance to think, write, rewrite, rewrite, and rewrite again; hence, the impetus for this writing retreat.

Academic journal writing is a specific kind of technical writing that requires mentoring (Kempenaar \& Murray, 2017; Thein \& Beach, 2010), including mutual engagement in collaborative research, co-authored research, reciprocal review and evaluation, and networking. However, as noted by Andrews et al. (2015), this type of mentoring is often not provided to Deaf doctoral students for several specific reasons. First, few doctoral programs in the U.S. are bilingual, providing content in American Sign Language (ASL) with written content in English. Therefore, most Deaf doctoral students are required to access content in spoken English through accommodations, limiting their ability to engage in both formal and informal doctoral discussions using direct communications. Given this situation, Deaf students are less likely to be invited to engage in collaborative and co-authored research with faculty mentors. Next as noted in Braun et al. (2017), Deaf doctoral students who had Deaf or Deaf Know (those who could communicate in ASL) mentors gained more social capital in terms of publications and navigation capital than those with mentors who were unable to directly communicate with them in ASL. Without this type of mentor, Deaf students tend not to be seen as someone who can contribute to reciprocal review and evaluation of their advisors or peers' work. Another important component is networking at conferences (Listman \& Dingus-Eason, 2018; Thein \& Beach, 2010), which is frequently not accessible to Deaf doctoral students. Importantly in terms of navigation capital, many conferences will provide interpreters for sessions that Deaf individuals request to be interpreted prior to coming to the meeting but most conferences do not provide interpreters for sessions not requested early or for informal networking opportunities (Braun et al., 2017). Finally, many Deaf individuals do not trust their ability to produce products in 
written English (Houston, 2018).

These are barriers that could plausibly interfere with Deaf academics in learning how to write for an academic publication. Two frequently written about barriers are the hidden curriculum and audism, both of which are belief systems that are detrimental to Deaf students' learning (Ballenger, 2013; Foster, 1989).

\section{The Hidden Curriculum}

The hidden curriculum refers to the unwritten rules typically learned through interactions with peers and supervisors (Acker, 2001; Acker \& Haque, 2017; Margolis \& Romero, 2002). Learning this hidden curriculum leads to success in academia; however, not having access to the hidden curriculum maintains the status quo of higher education and serves to block success for those not typically represented within the academy. A lack of mentoring to provide Deaf students access to this hidden curriculum from hearing faculty is often supported by audism.

\section{Audism}

Audism is defined as a group of people who use their hearing status to "discriminate ... against individuals based on hearing ability" (Bauman, 2004: p. 240). Like the hidden curriculum, audism is a belief system that blocks opportunities for Deaf academics to thrive in a university environment. Similar to female academics and administrators who hit the "glass ceiling" and have taken decades to break through the "good old boy" network, Deaf academics often face prejudicial attitudes and belief systems which keep them out of academic communities of practice (Houston, 2018; Kensington-Miller, 2018; Lave \& Wenger, 1991; Wenger et al., 2002).

Most hearing professionals are not aware of their own audist beliefs. Many do not realize that these perceptions form low expectations about Deaf learners (Braun et al., 2017). These attitudes may lead to the exclusion of Deaf researchers' perspectives that can provide an essential lens using the frame of Deaf history, its heritage and collective experiences of Deaf individuals (Hauser et al., 2010; Reagan et al., 2020). Thus, as originally defined by Humphries (1975), audism functions in a parallel manner to racism where beliefs and expectations lead to the belief that Deaf people "can't" write. Contrary to such audist beliefs, Hauser et al. (2010) and his team found that a Deaf perspective provides resilience against this audistic perception. Unfortunately, many Deaf individuals have internalized audism. Then these audist beliefs intertwine with the hidden curriculum, creating the imposter syndrome (Bothello \& Roulet, 2019) and a lack faith in these Deaf professionals of their own abilities.

Spooner (2020) noted that one comment frequently given to Deaf writers, is that they are told they are "good writers" with the unstated follow up "for a deaf person." Such microaggressions lead to reduced motivation and self-doubt about their writing abilities (Sezer et al., 2018). Therefore, Deaf students miss the opportunities to learn and become comfortable with academic writing, which prevents them from publishing articles. Thus, we can see that the hidden curriculum and 
audism effectively prevents opportunities for developing mentoring relationships in a safe and friendly environment. This gap can be "bridged" through the creation of a collective writing community (Bauman, 2004; Kensington-Miller, 2018; Lave \& Wenger, 1991; Wenger et al., 2002) that includes Deaf academics within a structure often referred to as a community of practice.

\section{Community of Practice}

A community of practice is a social learning environment composed of three parts: a domain (knowledge), community (groups of experts and students), and practice (shared expertise of experts; Wenger \& Snyder, 2000). The domain is a competence that is developed and shared by the community. This community learns from each other to increase their expertise, to help and support each other, while building relationships to promote the domain. The practice develops from shared stories and practices that build the expertise of the domain. Communities of practice develop professional skills, solve problems quickly, transfer best practices, and as noted by Wenger and Snyder (2000) these communities renew themselves and therefore "give ... the golden eggs and the goose that lays them" (p. 143).

By developing a community of practice for Deaf academics for purposes of learning to write for academic publications, this effort can provide access to the hidden curriculum of academia, which can help to overcome audism regarding the criticism around written English while creating the knowledge of how to publish peer reviewed articles (Kensington-Miller, 2018; Lave \& Wenger, 1991; Thein \& Beach, 2010; Wenger et al., 2002). The community teaches these academics how to solve problems and minimizes the stress of technical writing (Andrews, 2003).

Another added value to creating a community of practice is to provide additional mentoring to Deaf scholars in order to fill in the gaps not addressed during their doctoral programming (Thein \& Beach, 2010). Moreover, Deaf scholars can network with other Deaf scholars and mentors and plan for future research collaborations (Listman \& Dingus-Eason, 2018).

To our knowledge, there are no publications on the formation of writing retreats that are designed specifically for Deaf scholars. To meet this void in the literature and taking into consideration features such as the barriers and the need for the establishment of writing retreats for Deaf academics, this study was conceptualized and implemented. In designing the PAH! Academic Writing Retreat, it was important to infuse elements of Deaf culture into everyday teaching during the workshop by ensuring that ASL was the language of instruction and discussion, that a Deaf-friendly environment was set up, and that rules related to DeafSpace were followed. DeafSpace refers to removing architectural barriers such as making sure that there is sufficient lighting in the room, furniture is arranged so all students are in view of each other to see their signing, and the Deaf rules of discourse were followed during interactions (Edwards \& Harold, 2014). Due to the inclusion of these factors in other contexts, this retreat was developed 
to determine the efficacy of this type of niche on publications.

\section{Purpose}

The PAH! Academic Writing Retreat was formed specifically to create a community of practice that is conducted in sign language to create a Deaf centric curriculum (Hauser et al., 2010) to overcome audism and the microaggressions often experienced by Deaf writers. To further explore its efficacy we queried the participants, both mentors and mentees during and after the retreat. Using observations, reviews of documents, and interviews with mentors and mentees who participated in the retreat we addressed the following two research questions:

1) What barriers did the mentors and mentees see to the writing/publishing process for Deaf academics?

2) How did the PAH Academic Writing Retreat build a "community of practice" among mentors and mentees?

\section{Method}

\section{Design}

A case study approach was used that investigates a real-life contemporary context or setting (Baxter \& Jack, 2008; Creswell \& Poth, 2018). The design of this study was a holistic single case study (Yin, 2017). The boundaries for this case study was the development of the PAH! Academic Writing Retreat, the mentors, the mentees, and the products that resulted from this event (Stake, 1995; as cited in Baxter \& Jack, 2008). This case study used document reviews regarding the development of the retreat, observations during the retreat, and interviews with the mentors and mentees. As such, it was based on a constructivist paradigm where truth is relative, and the meaning comes from the perceptions of the individuals involved in the case itself.

\section{Setting}

The study took place at Lamar University in Beaumont, Texas. This university is classified by Carnegie as a Doctoral/Professional university (Carnegie Classification, 2019).

\section{Recruitment and sampling strategy}

Deaf academics who had data to be written up for publication were recruited through purposeful and snowball sampling (Creswell \& Poth, 2018). Lamar University Deaf Studies and Deaf Education's Facebook page served as an additional recruiting vehicle with both English text and an ASL video to inform people of the opportunity to participate in the retreat. Participant selection was based on the following characteristics: Deaf individuals who used sign language as their primary language, who were in a graduate program or had a graduate degree, and who had data that they had already collected and wanted to write up for publication.

After participants signed up for the PAH! Writing Retreat, they were sent an email with instructions to ensure that the participants were prepared for the intensive writing retreat. The first instruction was to ask that everyone coming to 
the retreat write up a brief abstract or summary of their project to share with other participants to give everyone the opportunity to review and become familiar with their projects. The second expectation for the writers was to use Google Documents as the platform to share our work. This platform allowed everyone, especially the mentors, to give feedback while the mentees wrote. Third, we were expected to meet twice or three times during the evenings after $5 \mathrm{pm}$. outside of our 8 am to $5 \mathrm{pm}$ writing sessions to discuss, brainstorm, and provide feedback on our work. The ultimate goal of the writing retreat was for each participant to complete their project.

\section{Participants}

Ten individuals participated in the retreat: four mentors and six Deaf mentees. The mentees included four Lamar University doctorate students/candidates, and the other two participants already had doctorate degrees, one from Lamar University and the other from Gallaudet University. One doctoral candidate worked on the method section of his dissertation, and the other three candidates/students worked on compiling a manuscript from a recent project. Finally, the two other mentees' goal was to publish an article from their dissertation. All but one mentee was working on writing up their first manuscript for submission to a peer reviewed journal. The mentors included the first author and the last two authors as well as another Deaf faculty member from Lamar University. Given that the last two authors are hearing and used ASL as a primary mode of communication during the retreat, it was critical that they recruit Deaf faculty to join in this project. They invited two Lamar University Deaf faculty members, who had recently graduated and are strong writers, to join the team.

\section{Logistics of the PAH! Academic Writing Retreat}

One of the implicit goals of this retreat was for mentees to later become mentors and continue to mentor other Deaf researchers to increase the number of Deaf academics who are successful in climbing the tenure ladder. The logistics of the day included four mentors working closely with six mentees. All projects were posted on Google Documents so that multiple people could work on the same manuscript.

\section{Positionality of the Research Team}

The five authors, all faculty members, comprise a collaborative team of three Deaf and two hearing individuals. Each has ties to the Deaf Studies and Deaf Education doctoral program at Lamar University in Beaumont, Texas, either as an active faculty member, retired faculty volunteer, or as an alumnus. Besides three faculty members at Lamar University, one author is a current faculty member at Gallaudet University in Washington, DC, and another author is currently a faculty member at the University of Houston as an instructional assistant ASL professor, thus providing a diversity of university perspectives.

\section{Results}

The retreat resulted in several products, reflections, a presentation, and this pa- 
per. Mentees either submitted their work or continued their work after the retreat, which reflects that sometimes more time is needed for publishing. The reflections highlight considerations, categorized by themes along with an overarching theme, discussed below, and provide insights regarding future retreats. Due to the need for more mentoring models, we presented at a conference to share our model, and that presentation led to this paper.

\section{Final Products}

At the end of the five days, we had several products. The mentee working on his dissertation had changed his methodology and learned how to redesign his dissertation. The alumni had created a draft paper that she continued to work on with the two more senior mentors who she had asked to become authors on the paper. This paper received feedback, was rewritten, and has been published. The other faculty member submitted her manuscript, and it was accepted; however, she never completed the revisions, and the paper was not published. The final group of three students continued to work on their paper after the retreat due to the unexpected complex analysis, and that paper has now been published. As most of the mentors and mentees were local, this was noted as being an effective context. However, as this event was the first retreat, there were areas that needed work and that include strengthening mentors, improving logistics, and providing structure.

What worked during the retreat?

As a part of reflections, mentors and mentees were asked what worked during the retreat, and two themes emerged: providing support and guidance, and convenience. Mentees found support and guidance from mentors beneficial in providing them with the capital or resources needed for academic writing and publishing. Additionally, as several mentors and mentees lived locally, they found attending the retreat convenient and that it kept costs down while it fit into their schedules.

Providing support and guidance. Providing support and guidance appeared as the primary benefits of the workshop. A mentee shared, "It was always helpful when a mentor sat with us discussing our papers, providing us with some ideas and guided us in writing using a more structured way." Another mentee stated, "The critical key was the face-to-face interactions during the retreat; that was a huge benefit for me. This retreat was designed for me to invest my time to focus on my writing with my mentor." A mentor shared, "Revisions for the novice writer are often hard to take as no one likes criticism. But peer feedback is a hallmark of peer-reviewed journal writing and learning 'how' and 'what' to accept in reviews is a lesson that all experienced writers must learn." Therefore, the overarching goal of the retreat was successful.

Convenience. The quotes below reflect the benefits of having a local retreat and may be more feasible for certain purposes. A mentee shared, "When it ended up being hosted at Lamar University; it was feasible for me to attend as I lived in the town and did not need to pay additional cost for travel, food, lodg- 
ing, and pet sitting." Another mentee shared, "It made sense for me to attend since I was living in the same city and I wouldn't have to pay for any of the traveling cost." One mentor shared, "The project would be 'local' so I could fit it into my schedule in my retirement to volunteer a week to assist as a mentor." This reflects an important consideration when establishing a retreat, especially if a concern is in how to keep costs down.

What needs to be improved? Another part of the reflections asked mentors and mentees what needed to be improved during the retreat, and three themes emerged: strengthening mentors, providing structure, and retreat logistics. Mentors and mentees agreed that the mentors need to be clearer regarding their roles and that the retreat needed to be structured differently to maximize the mentoring experience. Additionally, mentors and mentees agreed about the importance of having a DeafSpace to ensure that they were in an environment that included windows, bright lights without direct lighting, and where everyone is visible to each other.

Strengthening mentors. The dynamics of the group with both the mentors and mentees appeared not to be as effective as it could have been if it were structured differently. The challenge emerged due to two mentors who were quite experienced compared to two faculty members who were new and less familiar with the role of mentoring. A mentee shared, "There were a total of four mentors, two were experienced hearing faculty members and the other two were two inexperienced Deaf faculty members. These two younger mentors seemed to be unsure of themselves, the mentees really picked up on that." Another mentee shared, "...I think the retreat should have been staffed with four experienced mentors...I think the two junior faculty members should have attended as mentors-in-training to learn the ropes first." These concerns reflect a need to ensure enough mentoring resources are provided for the mentees.

Clearly, we need to provide more training for junior mentors. In the first retreat, the senior mentors had a lot of experience mentoring, and entered into the retreat expecting everyone to already understand how the writing and collaborative process worked. One senior mentor stated that she expected that she "would work with a mentee and lead her/him to publication. Also, to provide mentorship to others by reviewing their work." While the two senior mentors had already developed a collaborative writing style, the junior mentors had not yet acquired as much experience. One senior mentor simply "expected the junior mentors to be able to observe and jump into the process." Therefore, it never crossed her mind "to set up expectations or a structure to guide the junior mentors into the process." Just because the junior mentors had successfully completed their dissertation and had some publications under their belts, did not mean they were ready to assume all the challenges in the writing retreat. In short, they needed support in teaching about writing (i.e., mentoring writers) just as the mentees needed support in learning to write for academic journals.

The two junior mentors expressed concerns about the rank and age of partic- 
ipants as some were older than them. One who thought it would be simply helping with writing became concerned when learning of who was attending, stating that his concerns "were (with) age and rank, (as) many of the participants were older than me, which made it a little awkward." Another mentor was nervous because "many of them (mentees) already had well-developed English skills and may not see me as ... being beneficial."

This information highlights the impact of needing to "prove" that one has the skills by the junior mentors while the more senior mentors simply assumed that they had those skills. One junior mentor stated in reflections "that I don't think hearing mentors have these power dynamic challenges or may not be aware of them as they are automatically seen as the 'superior' due to age and the status quo of the system that has always showcased hearing people as academics." Importantly, the senior mentors had selected the junior mentors because they believed that they did have the skills needed and as noted, above did not notice these power dynamics. Therefore, more preparation and discussion of how to approach the task would have benefited the junior mentors as they would have gained more confidence in what they brought to the retreat.

Providing structure. Writing is not an easy endeavor for even prolifically published fluent English writers. It is a myth that published writers simply sit down and write a piece, send it off, and it becomes published. One mentee stated, "I did feel frustrated because I thought I would complete the paper within a day or two." Writing is a thinking process that involves time, effort, persistence as well as language skills. Writing requires grit.

Some mentees noted what to them was a lack of structure, which was difficult for those who were new to this process and unfamiliar with collaborative or co-writing. Some mentees seemed to have a difficult time making structure for themselves, rather they wanted an externally provided one. One mentor commented how the lack of structure influenced some individuals to wander off point, noting; "chatting did become a bit of a problem at the end for my team," and also commented that she was not "an early bird" and wanted to have more flexible hours.

A mentee stated that the experience of collaborative writing with both hearing and Deaf mentors was rewarding as she was able to receive direct feedback and genuine compliments about her work. She shared that this experience was different from what she had experienced in the past where she felt that her work was being minimized or that the mentor changed the entire content of her work. However, she felt that the structure needed to be clearer on how to provide feedback without "taking over" writing the paper. As such, we decided to add more structure in future retreats.

Retreat logistics. Logistics refers to proper management of space, resources, and time. For example, having a comfortable space or environment with resources such as Internet, computers, white boards, pen, pencil, paper are critical resources that must be factored in the logistics planning for the retreat. A men- 
tee had expressed that the internet was not easily accessible as her laptop was owned and restricted by her University. Therefore, it became a problem for her to obtain internet access on campus.

For a workshop with Deaf participants, the mentors must be sensitive to DeafSpace, an architectural term that relates to making the space visually accessible to Deaf participants. Tables and chairs must be set up so all can visually see other participants for communication. Attention needs to be made to the quality of the lighting where the lights should strategically be placed upward rather than down to avoid issues for the participants' eyes, glare, and the reduction of "visual noise." Therefore, an area that needed improvement was to find a room that had windows, in addition to providing natural light. A mentor shared, "The working environment was in my opinion not conducive to creativity. We were in an enclosed room, no windows, and it was claustrophobic with lots of intensity going on." The mentor added a quote by Virginia Woolf, "I need 'a room with a view"'.

Regarding the schedule of a 9 - 5 workday throughout the entire week without official breaks, a mentee shared, "I think there needs to be an official schedule with built in breaks and at least $1-2$ nights off or a later start in the morning. Perhaps to accommodate the early birds and night owls, schedule a common time in the middle of the day and those who want to work early can show up early. Those who want to work late can stay later." Feedback regarding the logistics of physical layout and schedule have been taken into consideration to meet a larger range of preferences among mentors and mentees.

\section{Overarching Theme}

Throughout data analysis the overarching theme, either implicit in comments or explicitly stated, was thoughts and feelings about what it means to be a Deaf person who is bilingual and experiencing diverse issues with English including fluency, systematic oppression, a self-fulfilling prophecy, and societal perspectives.

Impact of audism and hidden curriculum. There is a general perspective that to succeed in a career, you must have excellent English skills. As such is the case for Deaf persons, having excellent English skills is oftentimes perceived as that individual being more intelligent and competent. However, over time certain Deaf individuals have realized, especially with the recognition of ASL as a language, that this idea is not necessarily true. Unfortunately, the belief in the superiority of English skills is still prevalent and influential, which seems to justify the belief that having English skills is superior to having ASL skills. Such discriminatory thinking is audism. Such audistic thinking is often internalized by Deaf persons themselves as shown in these reflections. One stated:

I feel like an imposter by trying to be a scholar, it does have a huge impact on personal perspective and insecurity ... to have the courage to take the next step ... to create, and to innovate.

These concerns had already emerged before the retreat and carried over to the retreat itself. One mentor shared: 
Many of our participants have a fear of judgment that comes with writing. I suspect this is the product of years of audism. You can only be told you are 'no good' so many times before it becomes part of one's reality. I think the blocks Deaf writers have are largely psychological. They are not actual blocks as a matter of ability.

Another mentee noted the following as reflecting audism.

Deaf people are generally very sensitive about their writing, so it needs to be framed in a manner that belies a warm, nurturing, and supportive environment for writers of ALL levels. I know that working with experienced mentors during the writing process (whether official retreats or not) was greatly beneficial to me.

But these insights about combating audism arose from discussing writing abilities. For instance, one mentor asked, "Is a Deaf person's article really their own work? How do we know?" Then, another mentor responded, "I don't see anything wrong with a Deaf person signing what they want to have written down and a hearing person writing it down; that would be using both individuals' strengths." These interactions were interesting in terms of how Deaf and Hearing collaborative teams can work taking advantages of both languages to develop an academic paper.

\section{Conference Presentation}

The full team was invited to submit an abstract to a Deaf conference for possible presentation. The presentation was accepted but given the luck of the draw, it was scheduled during the last session of the conference. The team knows that this time period is simply luck, and everyone is scheduled for that slot at some point; therefore, our expectation was that few, if anyone, would show up for the presentation. In contrast, the room was full. The audience was highly engaged with the presenters, and when time was up, only the monitor left the room. The responses to this presentation were overwhelming for this team. One of our alumni offered to financially support this project in the future. A young Ph.D. student stated that she had chills in response to the presentation. In addition, she was crying as she was so touched that we would provide this opportunity for Deaf researchers. During this meeting, numerous members of the audience asked if we planned to write up this activity as a paper; the three of us who were there looked at each other and stated, "No, we had not planned on that." However, after these responses we decided to analyze this event as a case study in the hope that others can replicate our process and provide this type of opportunity to develop a community of practice for more future Deaf researchers.

\section{Discussion}

Overall, the retreat was successful as can be seen in the comments from both the mentors and the mentees. Additionally, all but one project has been completed. The dissertation was defended this spring, the one article with the two mentors 
and one mentee is published, and the group project is also published. The one manuscript accepted and not revised is the only project that will not be completed. This leads to two insights; the first is that audism is a persistent and invasive struggle for Deaf people (Bauman, 2004; Houston, 2018). Writing for many Deaf academics leads to high levels of anxiety. In this way, English becomes a gatekeeper and limits their ability to advance through the academic ranks, which requires published research in English. In addition, the post-retreat discussion revealed that the imposter syndrome (Cope-Watson \& Betts, 2010; Hutchins, 2015) can lead to lower levels of productivity in academia, especially with Deaf academics.

The hidden curriculum was found to be another gatekeeper. Mentees mentioned that most had not been invited to join in joint publications with their Ph.D. advisors. Acker (2001) and Acker and Haque (2017) noted that doctoral students in her studies felt unprepared regarding issues related to writing, publishing, as well as responding to peer review and editors' feedback. These comments reflect the barrier experienced by one mentee, whose paper was accepted with revisions; however, she was unable to complete these revisions after the retreat as she was not confident enough in her abilities to independently do what were in fact extremely minor revisions.

One important tenet of the hidden curriculum is to not confront your professors if you want to find a mentor among faculty who may see your ideas as threatening (Margolis \& Romero, 2002) and do not aggravate them if you want support (Marchut 2017; Moges-Riedel, 2020). Making the hidden curriculum explicit within the PAH! Academic Writing Retreat included the mentees' worldview and provided support within a more Deaf-centric framework allowing them to become successful.

Here we find ideas on how to create a successful community of practice for Deaf academics (Andrews \& Covell, 2006). One of the most important components is that the retreat be accessible; PAH! used ASL as the lingua franca. Here, Deaf academics have direct access to information, rather than having to rely on interpreters. This structure was noted as the most important criteria in research for successful Deaf-hearing partnerships (Wolsey et al., 2017). Results also point to the need for a safe environment without criticism for Deaf writers; this structure was only partially achieved in the first PAH! Retreat. However, feedback allowed new structures to be developed for the following PAH! Retreat. A missing component was aspirational capital (Braun et al., 2017) as the Deaf mentors were not confident in their roles. Regardless, results again point to new structures that were implemented in the next retreat. Here Yosso's (2005) ideas of cultural capital are seen as critical in that linguistic capital, navigation capital, and social capital as well as aspirational capital are necessary within this community of practice.

Feedback from both mentors and mentees were implemented in the second PAH! Writing Retreat that occurred in 2019. This retreat had additional Deaf 
mentors, all of whom were more senior than those in the 2018 retreat. Additionally, one of the 2018 Deaf mentors participated in the 2019 retreat, gaining more experience. Finally, the 2019 retreat had more planning meetings prior to the event while the 2018 retreat had no planning meetings. Therefore, the participants' responses from the 2018 retreat were instrumental in redesigning the 2019 retreat.

Given these comments, the second PAH! Writing Retreat in 2019 was a collaboration between Lamar and another Deaf-centric university and included six experienced mentors. This structure eliminated the imbalance in mentors and provided a more effective mentoring process. Interestingly, several mentors wanted to become mentees and later established smaller retreats to accomplish the collective goal of increasing Deaf-authored publications.

This community of practice continues even now in 202, when that retreat moved to an online format given COVID restrictions about travel. Initially the 2020 retreat was cancelled but one member of the community asked the mentors to reconsider as she felt that this structure was helping her to earn tenure. The two senior PIs, one from Lamar and the other from another Deaf-centric university, met online and agreed to give a virtual retreat a try; both of us were pleasantly surprised by how well it worked. This 2020 experience highlights that it is the use of sign language with structured feedback built into each day that supported the development of this community of practice. The other critical component is well published mentors who understand that many Deaf individuals have been traumatized by various individuals and microaggressions implications that they have weak abilities in using written English. Interestingly, the Deaf-centric university is in the process of changing the name of their department from English to Literacy to reduce this fear and imposter syndrome that is often found even among highly successful Deaf academics (Cuculick, personal communication December 18, 2020).

The community of practice continues to this day with past members joining in different writing venues created at Lamar. It has become a place to get feedback when experiencing writer's block, help with understanding feedback on manuscripts, and the encouragement to write, rewrite, and rewrite yet one more time.

\section{Limitations}

This case study was developed retrospectively, and some reflections were collected later after the completion of the retreat. This time delay may have increased variability in recall or distortions from off-line communications among mentors and mentees over about an eight-month period between the retreat and collecting the reflections.

Finally, the 2018 retreat was a pilot to determine if this type of retreat is needed. That meant that some of the participants were earning course credit, which may have led to differences in motivation. However, given the outcomes from 2018 and the response at the conference in early 2019, it seems clear that a 
safe space for Deaf academics to overcome their concerns or fears about writing can make a contribution to Deaf Studies and Deaf Education.

Another limitation is that this first year's PAH! Retreat did not consider the interactions of racism and audism. Recent work is expanding on these intersections (Moges-Riedel, 2020) and developing critical approaches to what a recent study label Deafnormativity (Wright, 2020) which questions "who belongs to Deaf culture?". In contrast to the 2018 retreat, the 2019 retreat included two Black Deaf mentees and a Latinx mentee. Then during the 2020 retreat there was a Black Deaf mentor who worked closely with the mentees of color. This most recent retreat included discussions and a few conflicts about both white and hearing privilege. Future research should include focus groups to clarify how best to support BIPOC Deaf scholars.

\section{Future Research}

Ongoing retreats have included discussions about other Deaf-centric universities joining this evolving community of practice. This expanding community then can include more Deaf faculty. This mixing of different universities provided more senior Deaf mentors and increased the diversity among the mentees. Moreover, mentees and mentors did not know each other prior to the retreat. Additional research regarding the mentoring experiences of Deaf doctoral students may create new ways to transfer cultural wealth, during doctoral studies and help Deaf individuals be more prepared as they obtain tenure track university positions. These investigations should include the most recent publications that investigate Black Deaf Gain (Moges, 2020) and the investigations around Deaf Lat Crit (García-Fernández, 2014).

\section{Conclusion}

In conclusion, the PAH! Academic Writing Retreat in 2018 helped to create a model to develop communities of practice for Deaf academics. Findings help to redesign the model to include more effective ways to transfer cultural wealth for future retreats. The effects of audism were clearly evident and the need for safe spaces to admit to one's limitations while gaining support to overcome those limitations was evident. Components of the hidden curriculum became overt to participants, which can lead to ways to better prepare future doctoral students by helping them to select appropriate programs and find supportive mentors that will engage them in scholarship during their coursework so that they can more effectively navigate the tenure system here in the US. It is hoped that others can use this model to increase opportunities for Deaf communities of practice across the country.

\section{Acknowledgements}

During the PAH! Academic Writing Retreat in 2018, participants in the writing retreat and Professor/Chair, Dr. M. Diane Clark and Emeritus Professor, Dr. Jean Andrews, decided to further explore and discuss the concept of mentoring 
of Deaf doctoral or postdoctoral students. The team of authors led the project by presenting at the 2019 Association of College Educators, Deaf and Hard of Hearing conference in Chicago, IL and realized we need to disseminate our findings as well as providing a possible model for mentoring. The authors wish to thank the PAH! Academic Writing Retreat for their contribution as a part of this project.

\section{Conflicts of Interest}

The authors declare no conflicts of interest regarding the publication of this paper.

\section{References}

Acker, S. (2001). The Hidden Curriculum of Dissertation Advising. In E. Margolis (Ed.), The Hidden Curriculum in Higher Education (pp. 61-78). New York: Routledge.

Acker, S., \& Haque, E. (2017). Left Out in the Academic Field: Doctoral Graduates Deal with a Decade of Disappearing Jobs. Canadian Journal of Higher Education/Revue canadienne d'enseignement supérieur, 47, 101-119. https://doi.org/10.7202/1043240ar

Andrews, J. F. (2003). Benefits of an Ed.D. Program in Deaf Education: A Survey. American Annals of the Deaf, 148, 259-266. https://doi.org/10.1353/aad.2003.0015

Andrews, J. F., \& Covell, J. A. (2006). Preparing Future Teachers and Doctoral-Level Leaders in Deaf Education: Meeting the Challenge. American Annals of the Deaf, 151, 464-475. https://www.jstor.org/stable/26234408 https://doi.org/10.1353/aad.2007.0000

Andrews, J. F., Byrne, A., \& Clark, M. D. (2015). Deaf Scholars on Reading: A Historical Review of 40 Years of Dissertation Research (1973-2013): Implications for Research and Practice. American Annals of the Deaf, 159, 393-418.

https://doi.org/10.1353/aad.2015.0001

Ballenger, S. (2013). Strategies to Avoid Audism in Adult Educational Settings. Adult Learning, 24, 121-127. https://doi.org/10.1177/1045159513489115

Bauman, H.-D. L. (2004). Audism: Exploring the Metaphysics of Oppression. The Journal of Deaf Studies and Deaf Education, 9, 239-246. https://doi.org/10.1093/deafed/enh025

Baxter, P., \& Jack, S. (2008). Qualitative Case Study Methodology: Study Design and Implementation for Novice Researchers. The Qualitative Report, 13, 544-559. https://nsuworks.nova.edu/tqr/vol13/iss $4 / 2$

Bothello, J., \& Roulet, T. J. (2019). The Imposter Syndrome, or the Mis-Representation of Self in Academic Life. Journal of Management Studies, 56, 854-861.

https://doi.org/10.1111/joms.12344

Braun, D. C., Gormally, C., \& Clark, M. D. (2017). The Deaf Mentoring Survey: A Community Cultural Wealth Framework for Measuring Mentoring Effectiveness with Underrepresented Students. CBE-Life Sciences Education, 16, ar10.

https://www.lifescied.org/doi/pdf/10.1187/cbe.15-07-0155

https://doi.org/10.1187/cbe.15-07-0155

Collier, M. L. (2011) v. Texas Tech University, No. 2008-545, 781. Lubbock County District Court, 99th, Lubbock, Texas.

Cope-Watson, G., \& Betts, A. S. (2010). Confronting Otherness: An e-Conversation between Doctoral Students Living with the Imposter Syndrome. Canadian Journal for New Scholars in Education/Revue canadienne des jeunes chercheures et chercheurs en éducation, 3, 1-13. https://journalhosting.ucalgary.ca/index.php/cjnse/about 
Creswell, J. W., \& Poth, C. N. (2018). Qualitative Inquiry and Research Design: Choosing among Five Approaches (4th ed.). Washington DC: Sage Publications.

Edwards, C., \& Harold, G. (2014). DeafSpace and the Principles of Universal Design. Disability and Rehabilitation, 36, 1350-1359. https://doi.org/10.3109/09638288.2014.913710

Foster, S. (1989). Reflections of a Group of Deaf Adults on Their Experiences in Mainstream and Residential School Programs in the United States. Disability, Handicap \& Society, 4, 37-56. https://doi.org/10.1080/02674648966780031

García-Fernández, C. M. (2014). Deaf-Latina/Latino Critical Theory in Education: The Lived Experiences and Multiple Intersecting Identities of Deaf-Latina/o High School Students. Unpublished Doctoral Dissertation, Austin, TX: The University of Texas. https://repositories.lib.utexas.edu/bitstream/handle/2152/25088/GARCIA-FERNANDE Z-DISSERTATION-2014.pdf? sequence $=1 \&$ isAllowed $=\mathrm{y}$

Hauser, P., O’Hearn, A., McKee, M., Steider, A., \& Thew, D. (2010). Deaf Epistemology: Deafhood and Deafness. American Annals of the Deaf, 154, 486-492.

http://www.jstor.org/stable/26235009

https://doi.org/10.1353/aad.0.0120

Houston, T. J. (2018). Defining Academia Influences on Mobility, Identity, and Culture of Deaf Scholars in Higher Education (Order No. 10830314).

https://proxyga.wrlc.org/login?url=https://www-proquest-com.proxyga.wrlc.org/docvi ew/2072338179? accountid=27346

http://carnegieclassications.ie.edu

Humphries, T. (1975). Audism: The Making of a Word. Unpublished Essay.

Hutchins, H. M. (2015). Outing the Imposter: A Study Exploring Imposter Phenomenon among Higher Education Faculty. New Horizons in Adult Education and Human Resource Development, 27, 3-12. https://doi.org/10.1002/nha3.20098

Kempenaar, L., \& Murray, R. (2017). Analysis of Writing Programmes for Academics: Application of a Transactional and Systems Approach. Studies in Higher Education, 43, 2371-2384. https://doi.org/10.1080/03075079.2017.1329817

Kensington-Miller, B. (2018). Surviving the First Year: New Academics Flourishing in a Multidisciplinary Community of Practice with Peer Mentoring. Professional Development in Education, 44, 678-689. https://doi.org/10.1080/19415257.2017.1387867

Lave, J., \& Wenger, E. (1991). Situated Learning: Legitimate Peripheral Participation. Cambridge: Cambridge University Press. https://doi.org/10.1017/CBO9780511815355

Listman, J. D., \& Dingus-Eason, J. (2018). How to Be a Deaf Scientist: Building Navigational Capital. Journal of Diversity in Higher Education, 11, 279. https://doi.org/10.1037/dhe0000049

Marchut, A. E. (2017). Persistence of Deaf Students in Science, Technology, Engineering, and Mathematics Undergraduate Programs (Order No. 10663160).

https://ui.adsabs.harvard.edu/abs/2017PhDT.......117M/abstract

Margolis, E., \& Romero, M. (2002). “In the Image and Likeness...”: How Mentoring Functions in the Hidden Curriculum. In The Hidden Curriculum in Higher Education (pp. 89-106). New York: Routledge. https://doi.org/10.4324/9780203901854-7

Moges, R. T. (2020). “From White Deaf People’s Adversity to Black Deaf Gain”: A Proposal for a New Lens of Black Deaf Educational History. JCSCORE, 6, 68-99.

https://doi.org/10.15763/issn.2642-2387.2020.6.1.68-99

Moges-Riedel, R. (2020). Few and Far between: Deaf Faculty of Color at Postsecondary Institutions. Doctoral dissertation. Northridge: California State University. 
Paul, P., \& Wang, Y. (2012). Literate Thought: Understanding Comprehension and Literacy. Sudbury, MA: Jones \& Bartlett Learning.

Reagan, T., Matlins, P. E., \& Pielick, C. D. (2020) Teaching Deaf Culture in American Sign Language Courses: Toward a Critical Pedagogy. Foreign Language Annals, 53, 270-291. https://doi.org/10.1111/flan.12453

Sezer, O., Brooks, A. W., \& Norton, M. I. (2018). Backhanded Compliments: How Negative Comparisons Undermine Flattery. Boston, MA: Harvard Business School. https://www.hbs.edu/faculty/Publication\%20Files/18-082 f96a8202-ccfe-409b-a8ba-0f1 87bf678e4.pdf

Smith, D. H., \& Andrews, J. F. (2015). Deaf and Hard of Hearing Faculty in Higher Education: Enhancing Access, Equity, Policy, and Practice. Disability \& Society, 30, 1521-1536. https://doi.org/10.1080/09687599.2015.1113160

Spooner, R. A. (2020). Permissive vs. Prohibitive: Deaf and Hard-of-Hearing Students' Perceptions of ASL and English. Sign Language Ideologies in Practice, 12, 167. https://doi.org/10.1515/9781501510090-009

Stake, R. E. (1995). The Art of Case Study Research. Washington DC: Sage.

Thein, A. H., \& Beach, R. (2010). Mentoring Doctoral Students towards Publication within Scholarly Communities of Practice. In Publishing Pedagogies for the Doctorate and Beyond (pp. 117-136). London: Routledge.

Wenger, E. C., \& Snyder, W. M. (2000). Communities of Practice: The Organizational Frontier. Harvard Business Review, 78, 139-146.

http://www.psycholosphere.com/Communities $\% 20$ of $\% 20$ Practice $\% 20-\% 20$ the $\% 20$ orga nizational\%20frontier\%20by\%20Wenger.pdf

Wenger, E., McDermott, R. A., \& Snyder, W. (2002). Cultivating Communities of Practice: A Guide to Managing Knowledge. Brighton, MA: Harvard Business Press. http://www.cpcoaching.it/wp-content/uploads/2012/05/WengerCPC.pdf

Wolsey, J. A., Dunn, K. M., Gentzke, S. W., Joharchi, H. A., Clark, M. D., \& CSEDL Team (2017). Deaf/Hearing Research Partnerships. American Annals of the Deaf, 161, 571-582. https://doi.org/10.1353/aad.2017.0007

Woodcock, K., Rohan, M., \& Campbell, L. (2007). Equitable Representation of Deaf People in Mainstream Academia: Why Not? Higher Education, 53, 359-379.

https://doi.org/10.1007/s10734-005-2428-x

Wright, S. J. (2020). Deafnormativity: Who Belongs in Deaf Culture? Disability \& Society, 1-19. https://doi.org/10.1080/09687599.2020.1787818

Yin, R. K. (2017). Case Study Research and Applications: Design and Methods. Washington DC: Sage Publications.

Yosso, T. J. (2005). Whose Culture Has Capital? A Critical Race Theory Discussion of Community Cultural Wealth. Race Ethnicity and Education, 8, 69-91. https://doi.org/10.1080/1361332052000341006 